\title{
Propagação de abacateiro via estacas estioladas
}

\author{
Henrique Belmonte Petry; Bibiana Della Pasqua Ferreira; Otto Carlos Koller; Vanessa Savian da \\ Silva; Sergio Francisco Schwarz $\left({ }^{*}\right)$ \\ Universidade Federal do Rio Grande do Sul (UFRGS), Faculdade de Agronomia, Programa de Pós-Graduação em Fitotecnia, Av. \\ Bento Gonçalves, 7712, 91540-000 Porto Alegre (RS), Brasil \\ (*) Autor correspondente: schwarz@ufrgs.br
}

Recebido: 2/ago./2011; Aceito: 5/nov./2011

\begin{abstract}
Resumo
Este trabalho objetivou testar um método de propagação de abacateiro a partir de estacas estioladas cultivadas em recipientes de diferentes alturas. $\mathrm{O}$ experimento foi desenvolvido em câmara de nebulização intermitente. O delineamento experimental foi em blocos ao acaso, em esquema fatorial 3x4, com três repetições, testando-se dois métodos de obstrução de seiva (anelamento da casca, estrangulamento da casca) e quatro alturas de recipientes para o substrato (10, 15, 20 e $25 \mathrm{~cm}$ ). Decorridos 250 dias, não se observou efeito da altura do recipiente na sobrevivência, no número de folhas desenvolvidas, na altura e no diâmetro das mudas formadas a partir de estacas estioladas. Houve maior sobrevivência e emissão de folhas nas estacas de casca anelada em relação à testemunha; as estacas de casca estrangulada situaram-se em posição intermediária. O prévio anelamento ou estrangulamento da casca de ramos estiolados aumentaram a sobrevivência e o crescimento de mudas na propagação de abacateiro da seleção Viamão, por estaquia.
\end{abstract}

Palavras-chave: Persea americana, obstrução de seiva, estaquia.

\section{Avocado propagation by etiolated cuttings}

\begin{abstract}
This research aimed to test a method of avocado propagation from etiolated cuttings in recipients with different heights. The experiment was carried out in an intermittent mist chamber. The experimental design was in randomized blocks with a $3 \times 4$ factorial and three replicates. Two methods of sap obstruction (girdling or strangulation) and four heights of containers (10, 15, 20 or $25 \mathrm{~cm}$ ) were tested. After 250 days, there was no effect of container heights on the survival, the number of developed leaves, plant height and diameter of the seedlings formed from etiolated cuttings. There was a higher survival rate and number of leaves in girdled cuttings as compared to control plants; cuttings obtained from the strangulation treatment had intermediate behavior. The previous bark girdling or strangulation of etiolated avocado branches increased survival and plant growth for the propagation of selection Viamão cuttings.
\end{abstract}

Key words: Persea americana, sap obstruction, cutting.

\section{INTRODUÇÃO}

O Brasil, com uma produção de 116 mil toneladas, em 2008, foi o sexto maior produtor de abacate do mundo, sendo responsável por cerca de $4 \%$ da produçáo mundial de 3.532.011 toneladas. Entretanto, em 1980, o Brasil já havia ocupado o terceiro lugar, evidenciando que a produção brasileira de abacate não cresce no mesmo ritmo de outros países, tais como México, Chile, Colômbia e Indonésia (FAO, 2010).

No Brasil, as mudas de abacateiros (Persea americana Miller e Persea nubigena Williams) são produzidas geralmente pela enxertia de uma cultivar-copa sobre um porta-enxerto oriundo de embriáo zigótico de semente monoembriônica (Koller, 2002). Devido à polinização cruzada, há grande variabilidade nos portaenxertos oriundos de sementes, sendo impossível obter plantas geneticamente uniformes, como é indicado para formação de pomares comerciais. Por conseguinte, apesar de enxertadas, as plantas divergem umas das outras, em vigor e produtividade, mas, principalmente na adaptabilidade a determinadas características dos solos e resistência ou tolerância a doenças como a gomose ou podridão das radicelas, causada por Phytophthora cinnamomi Rands (KadMAN e Ben YA'ACOv, 1965). A propagação vegetativa de um clone superior de abacateiro, por estaquia ou mergulhia, evitaria esse problema, porém existem alguns percalços na produção de mudas através destes métodos, como o excesso de compostos fenólicos, a rápida oxidação e desidratação dos tecidos, além da formação de calos sem a emissão de raízes.

Estaquia é o processo de propagação no qual a base de segmentos de ramos, geralmente de consistência semilenhosa, contendo ao menos uma gema axilar, é destacada da planta mãe e imersa em substratos propícios para a emissão de raízes adventícias (FACHINELlo 
et al., 1995), explorando assim a possibilidade das plantas regenerarem raízes a partir de um segmento de ramo, ou de um segmento de raiz (Fachinello et al., 2005; Hartmann et al., 2002).

Segundo Koller (2002), é difícil o enraizamento de estacas de abacateiro. Esta dificuldade, em diversas espécies frutíferas, segundo FACHINELlo et al. (1995), pode ser causada por fatores internos como: condição fisiológica da planta matriz, idade da planta, tipo de estaca, época do ano, potencial genético de enraizamento, sanidade, balanço hormonal e oxidação de compostos fenólicos; ou externos: luz, umidade, temperatura, substrato e condicionantes. A dificuldade de enraizamento parece ser uma característica comum a várias espécies da família Lauraceae (Iтон et al., 2002).

Dentre os fatores que beneficiam especificamente o enraizamento de estacas de abacateiro, são destacados: planta matriz jovem, utilização de estacas terminais semiherbáceas, temperaturas adequadas, uso de fitorreguladores, intensidade de luz reduzida, presença de folhas e uso de estacas estioladas (Kadman e Ben YA'acov, 1965).

$\mathrm{O}$ anelamento da casca de ramos provoca a interrupção temporal do transporte floemático para as raízes e propicia o acúmulo de substâncias na copa das plantas Salisbury e Ross (1994). Em estudos realizados com diversas espécies e cultivares cítricas, a concentração de fotoassimilados e fitormônios aumenta na porção acima do anelamento, aumentando a importância das folhas como fonte destes metabólitos, visto que as raízes são os órgãos de reserva mais eficientes (Agusti et al., 2007).

Segundo Young (1961), o enraizamento de estacas de abacateiro depende muito da variedade. Utilizando estacas de árvores adultas, variedades como Zutano e Scott frequentemente chegam a $100 \%$ de enraizamento, enquanto as estacas de 'Fuerte' têm baixo percentual de enraizamento e as de 'Hass' não enraízam.

Quanto à importância do estiolamento, BARRIENTOSPriego et al. (1986) não conseguiram enraizar estacas verdes de abacateiros 'Colin V-33 e 'Fuerte'. Porém, quando previamente estioladas, $25 \%$ das estacas destas duas cultivares emitiram raízes.

A hipótese deste estudo foi de que o estiolamento com a posterior obstrução da seiva das estacas de abacateiro poderia aumentar o enraizamento e a sobrevivência delas proporcionando um método de maior eficiência de propagação de porta-enxertos do abacateiro. $\mathrm{O}$ objetivo deste trabalho foi testar procedimentos de propagação de abacateiro por estaquia, para formaçáo de mudas e/ou de porta-enxertos, sobre os quais as cultivares-copa possam ser enxertadas para a formação de pomares.

\section{MATERIAL E MÉTODOS}

Os trabalhos experimentais foram realizados em Porto Alegre (304'14"S; 518'26”O), Rio Grande Sul.
Segundo a classificação de Köppen, o clima da regiáo é subtropical úmido de verão quente do tipo Cfa. A obtenção das estacas estioladas ocorreu através de nove etapas, que serão descritas a seguir e parte delas estáo ilustradas na figura 1 .

Etapa 1: Sementes de abacateiro 'Baronesa' foram semeadas, em março de 2006, em leito de areia, previamente desinfestada mediante rega com solução de $0,30 \%$ de Ridomil (metalaxil 80\%). A emergência das plântulas começou no início do mês de maio, aproximadamente 30 dias após a semeadura e prolongou-se até o fim de junho. $\mathrm{Na}$ medida em que as plântulas atingiam alturas entre 5 e $10 \mathrm{~cm}$, foram repicadas para vasos plásticos com $10,5 \mathrm{~cm}$ de altura, contendo substrato composto por uma mistura previamente desinfestada, com solução de formol 7\%, de Argissolo Vermelho-Escuro, areia, casca de arroz carbonizada e esterco de gado curtido na proporção de 3:2:2:1 respectivamente, para se desenvolverem em casa de vegetação.

Etapa 2: No fim de julho, ocasião em que as plântulas atingiram a altura de aproximadamente $30 \mathrm{~cm}$ e o diâmetro de caule de $1 \mathrm{~cm}$, foi feita a enxertia tipo fenda cheia, com garfos de ramos ponteiros de abacateiros da seleção Viamão, possivelmente tolerante à gomose.

Etapa 3: Quando os enxertos começaram a brotar, antes das brotaçóes atingirem $1,5 \mathrm{~cm}$ de comprimento, as plantas foram transferidas para a câmara escura, formada por uma armação de madeira (com 1,2 m de largura, $3,0 \mathrm{~m}$ de comprimento e $1,5 \mathrm{~m}$ de altura), coberta com lona de polietileno preta, objetivando que o enxerto desenvolvesse ramos estiolados. Foram mantidas somente as brotações provenientes do enxerto e as do porta-enxerto foram removidas semanalmente. No início de outubro, na medida em que as brotações dos enxertos atingiam comprimento igual ou superior a $10 \mathrm{~cm}$, os vasos foram retirados da câmara escura (Figura 1a).

Etapa 4: Cilindros metálicos, formados por lâminas galvanizadas e arqueadas, de $6 \mathrm{~cm}$ de altura e diâmetro de aproximadamente $10 \mathrm{~cm}$, foram colocados sobre o substrato contido nos vasos, envolvendo o colo das mudas e, a seguir, preenchidos com areia. Sobre a superfície dessa areia foi colocado um tubo de PVC com 7,5 cm de diâmetro interno e $15 \mathrm{~cm}$ de altura, preenchido com substrato de casca de arroz carbonizada, envolvendo as brotaçôes de cada enxerto. Desta forma, manteve-se estiolada a base da brotação, na extensão de 9 a $10 \mathrm{~cm}$ (Figura 1b). Após esse procedimento, as mudas foram levadas para uma câmara de nebulização intermitente e expostas à plena luz, para desenvolverem folhas clorofiladas na parte apical das brotações, possibilitando a produção de substâncias de reserva a partir da fotossíntese. Em novembro, um mês após esse procedimento, as mudas já tinham folhas verdes bem desenvolvidas.

Etapa 5: As mudas foram separadas em três grupos, de vinte e quatro mudas cada um, que receberam 
os tratamentos de obstruçáo da seiva, sendo eles: anelamento, estrangulamento da casca e testemunha. O anelamento das estacas foi realizado através do seguinte procedimento (Figura 1c): uma chapa galvanizada contendo uma abertura em forma de "U" foi inserida entre o anel galvanizado contendo areia e o tubo de PVC; a seguir, com o auxílio da mesma chapa, deslocou-se para cima, cuidadosamente, o tubo contendo a casca de arroz carbonizada, para deixar exposto o enxerto e a base da brotaçáo estiolada; com o auxílio de uma tesoura aneladora, realizou-se dois cortes paralelos, de $360^{\circ}$, separados $3 \mathrm{~mm}$ um do outro, seccionando a casca do enxerto $1 \mathrm{~cm}$ abaixo da inserção da haste estiolada e possibilitando, assim, a retirada de um anel de casca com $3 \mathrm{~mm}$ de largura; em seguida, baixou-se a chapa galvanizada e o tubo de PVC retornou à posição inicial. Em outro lote de mesma quantidade de mudas, utilizando procedimento semelhante, realizou-se o tratamento de estrangulamento da casca do enxerto (Figura 1d), também 1 $\mathrm{cm}$ abaixo da inserção da haste estiolada, amarrando um arame de cobre plastificado, moderadamente apertado com o auxílio de um alicate, para provocar, na medida em que este posteriormente crescia em diâmetro, progressivamente o estrangulamento da casca do enxerto, objetivando a gradual diminuição e interrupção do deslocamento de seiva elaborada para as raízes. O terceiro lote formou o tratamento testemunha, cujos enxertos náo foram nem anelados nem estrangulados.

Todas as mudas continuaram em câmara de nebulização intermitente e, a partir desta etapa, devido ao surgimento de leves sintomas de deficiência nutricional nas folhas, começaram a ser feitas aplicaçôes mensais de uma solução de adubo foliar Niphokam (1\%), composto de: $10,0 \%$ de $\mathrm{N} ; 8,0 \%$ de $\mathrm{P}_{2} \mathrm{O}_{5} ; 8,0 \%$ de $\mathrm{K}_{2} \mathrm{O} ; 1,0 \%$ de Ca; $0,5 \%$ de $\mathrm{Mg} ; 0,5 \%$ de $\mathrm{B} ; 0,2 \%$ de $\mathrm{Cu} ; 0,1 \%$ de Fe; $0,5 \%$ de Mn; e $0,1 \%$ de Mo.

Etapa 6: Em dezembro, decorridos 30 dias após a realização dos tratamentos, os tubos com o substrato de casca de arroz carbonizada foram removidos e as brotaçóes destacadas do enxerto, mediante corte feito com tesoura, na base de sua inserção. Em cada uma delas foram conservadas quatro folhas adultas, sendo as demais podadas; a seguir, as estacas foram classificadas por tamanho, para formação de blocos uniformes. Na base de cada estaca foi feito um corte em bisel acentuado; em seguida, a base de cada uma delas foi submersa durante 5 segundos em solução hidroalcoólica de ácido indolbutírico (AIB) a 5 g.L. $L^{-1}$. Para o plantio, foram utilizados tubos de PVC branco, com diâmetro de $7,5 \mathrm{~cm}$ e várias alturas $(10,15,20$ e $25 \mathrm{~cm})$, preenchidos com casca de arroz carbonizada. As estacas foram plantadas em profundidade média de $5 \mathrm{~cm}$ e os recipientes dispostos sobre banquetas de concreto com dimensôes de $1 \mathrm{~m}$ de largura por $3 \mathrm{~m}$ de comprimento, revestidas com uma camada de areia grossa de $2 \mathrm{~cm}$ de espessura (para drenagem), sob nebulização intermitente (Figura 1e).

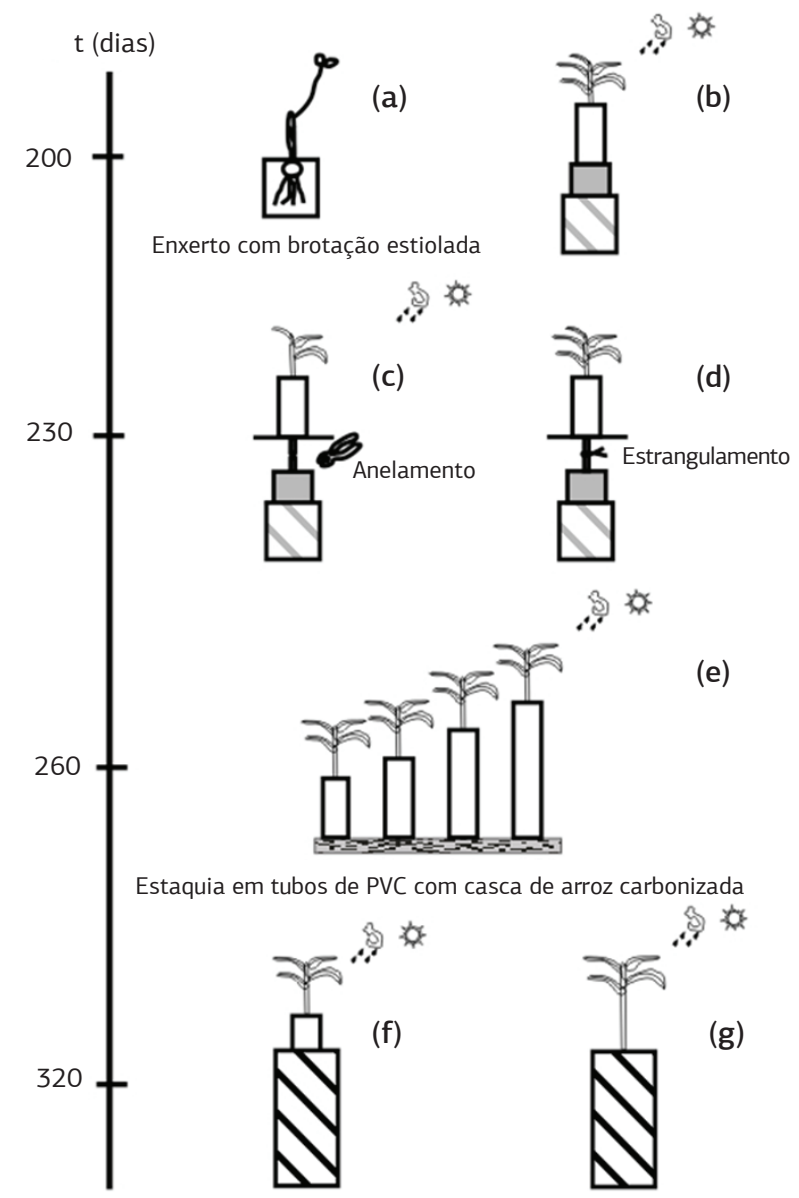

Figura 1. Esquema de produção de mudas de abacateiro a partir de estacas estioladas. (a) Etapa 3 - Enxertos com 1,5 cm de comprimento levados a câmara escura para estiolamento; (b) Etapa 4 - Enxertos estiolados com $10 \mathrm{~cm}$ de comprimento, com cilindro metálico de $6 \mathrm{~cm}$ de altura preenchido com areia e tubo de PVC de $15 \mathrm{~cm}$ de altura preenchido com casca de arroz carbonizada em sistema de nebulização a plena luz; (c) Etapa 5 - Aplicação do tratamento de anelamento da estaca com retirada de $3 \mathrm{~mm}$ de anel da casca; (d) Etapa 5 - Aplicaçáo do tratamento de estrangulamento da casca com arame de cobre plastificado; (e) Etapa 6 - Estacas transferidas para tubos de PVC de diferentes tamanhos e preenchidas com casca de arroz carbonizada, em condição de nebulização e plena luz; (f) Etapa 7 - Dois meses após a estaquia, com as estacas ainda dentro dos tubos de PVC, são transferidas para sacos de polietileno de $5 \mathrm{~L}$ com substrato de cultivo, em condição de nebulização e plena luz; (g) Etapa 8 - Sete dias após a transferência das estacas aos sacos de polietileno, são retirados os tubos de PVC e as mudas mantidas em câmara de nebulização e em plena luz.

Etapa 7: Dois meses após a estaquia, no início de março de 2007, as mudas, sem serem removidas dos tubos de PVC com casca de arroz carbonizada, foram transferidas para sacos de plástico preto com capacidade para $5 \mathrm{~L}$ de substrato, sendo este composto por uma mistura de Argissolo Vermelho-Escuro, areia, casca de arroz e esterco de gado curtido, na proporção de 3:2:2:1 (Figura 1f).

Etapa 8: Após sete dias da realização da etapa anterior, o tubo de PVC foi retirado puxando-o para cima, pelas bordas, sem deslocar a casca de arroz carbonizada. Para a adequada adaptação ao novo ambiente, as mudas 
permaneceram na câmara de nebulizaçáo intermitente por mais 15 dias (Figura 1g).

Etapa 9: Passado o período de adaptação ao transplantio, as mudas foram levadas para uma casa de vegetação com paredes de tela branca (clarite) e telhado de plástico, dispostas em canteiros protegidos dos raios solares por uma cobertura de tela sombrite. A partir de então, a irrigação foi realizada diariamente por aspersão.

Mensalmente, foram avaliados a sobrevivência de estacas $(\%)$, a altura $(\mathrm{cm})$, o diâmetro do caule $(\mathrm{cm})$ e o número de folhas emitidas pelas estacas. Não foram efetuadas avaliaçôes sobre o desenvolvimento de raízes, porque se pretendia manter o máximo de mudas, para, posteriormente, submetê-las à enxertia. As avaliaçóes se sucederam até 240 dias após a estaquia, considerando-se como enraizadas as plantas que sobreviveram neste período.

O delineamento experimental utilizado foi o de blocos ao acaso, em esquema fatorial $3 \times 4$ em parcelas subdividas no tempo, com três repetiçôes, testando-se dois métodos de obstrução de seiva (estrangulamento da casca, anelamento da casca) e testemunha, e quatro alturas de recipientes $(10,15,20$ e $25 \mathrm{~cm})$ na estaquia. Cada bloco foi composto por 12 tratamentos e cada parcela constituída por duas estacas. Os dados obtidos foram transformados em $(x+1)^{1 / 2}$, devido ao comportamento não gausiano dos dados e submetidos à análise de variância; as médias foram comparadas pelo teste de Tukey $(\mathrm{p}<0,05)$. Estas análises foram realizadas pelo programa computacional Assistat 7,5 Beta (Silva e Azevedo, 2002). As análises de regressão foram realizadas pelo programa computacional Sigma Plot 11.0 (Sigmaplot, 2008).

\section{RESULTADOS E DISCUSSÃO}

Após 240 dias da estaquia não houve diferença significativa entre as mudas em função da altura dos recipientes (tubos de PVC) que continham o substrato de enraizamento, mostrando uma vantagem no uso de vasos de $10 \mathrm{~cm}$ de altura pela menor necessidade de substrato e menor custo em tubos. Em relação aos tratamentos de obstrução da seiva elaborada, em estacas que receberam o anelamento houve maior sobrevivência $(73,6 \%)$ e número de folhas por planta $(8,4)$ que o tratamento-testemunha $(37,5 \%$ e 4,1 respectivamente), porém ambos não diferiram do tratamento de estrangulamento $(59,7 \%$ e 7,4 respectivamente), que tiveram valores intermediários (Tabela 1 ).

Quanto à altura atingida pelas mudas, nas estacas que receberam o tratamento de estrangulamento, o desenvolvimento superior ao verificado nos demais tratamentos e não houve diferença entre os tratamentos quanto ao diâmetro das plantas (Tabela 1). Em ambos os procedimentos de obstrução de seiva elaborada, as substâncias de reserva e cofatores de enraizamento devem ter se concentrado acima da regiāo obstruída (Oliveira et al., 2000) e, dessa forma, contribuíram para o aumento da sobrevivência e crescimento das estacas.

Quanto ao método de obstrução da seiva, FACHINELlo et al. (1988) não observaram diferenças entre as técnicas de anelamento e estrangulamento em ramos de porta-enxerto de macieira 'MM-106'. Nas pesquisas realizadas por esses autores, ambas as técnicas utilizadas proporcionaram, igualmente, melhor enraizamento das estacas, maior quantidade de matéria seca e maior quantidade de açúcares solúveis em relação à testemunha (sem anelamento ou estrangulamento). No entanto, em estacas de laranjeira 'Valência', o estrangulamento dos ramos não induziu aumento no número de estacas enraizadas nem melhorou o efeito do estiolamento (Castro e Kersten, 1996).

Através de análises de regressão da porcentagem de sobrevivência de mudas ao longo do tempo, em funçáo dos procedimentos de anelamento, obtiveram-se equaçóes que originaram curvas de natureza sigmoidal (Figura 2), nas quais se pode observar que a sobrevivência permaneceu estável, em $100 \%$, nos primeiros 20-25 dias e depois declinou abruptamente até 45-60 dias e

Tabela 1. Sobrevivência (\%) e dados biométricos das mudas de abacateiro seleção Viamão, obtidas a partir de estacas estioladas submetidas a dois métodos de obstrução de seiva elaborada e uso de recipientes com quatro alturas para o substrato de enraizamento, aos 240 dias após o início da estaquia

\begin{tabular}{|c|c|c|c|c|c|}
\hline Tratamentos & & $\begin{array}{c}\text { Sobrevivência } \\
\text { (\%) }\end{array}$ & $\begin{array}{l}\text { Folhas por planta } \\
\text { (unid.) }\end{array}$ & $\begin{array}{l}\text { Altura } \\
(\mathrm{cm})\end{array}$ & $\begin{array}{l}\text { Diâmetro } \\
\text { (cm) }\end{array}$ \\
\hline \multirow{4}{*}{ Obstrução da seiva } & Anelamento & $73,61 \mathrm{a}$ & $8,38 \mathrm{a}$ & 17,38 b & 0,42 \\
\hline & Estrangulamento & $59,72 a b$ & $7,42 \mathrm{ab}$ & $25,58 \mathrm{a}$ & 0,48 \\
\hline & Testemunha & $37,50 \mathrm{~b}$ & 4,08 b & $18,08 b$ & 0,42 \\
\hline & Média & 56,94 & 6,62 & 20,35 & 0,44 \\
\hline \multirow{5}{*}{ Altura do vaso $(\mathrm{cm})$} & 10 & 61,11 & 7,93 & 20,51 & 0,48 \\
\hline & 15 & 62,96 & 6,71 & 18,77 & 0,44 \\
\hline & 20 & 48,15 & 6,37 & 20,60 & 0,50 \\
\hline & 25 & 55,56 & 5,50 & 21,50 & 0,42 \\
\hline & Média & 56,94 & 6,62 & 20,35 & 0,46 \\
\hline CV (\%) & & 31,44 & 28,42 & 35,10 & 6,55 \\
\hline
\end{tabular}

Médias náo seguidas de mesma letra na coluna diferem pelo teste de Tukey a $5 \%$ de probabilidade. 


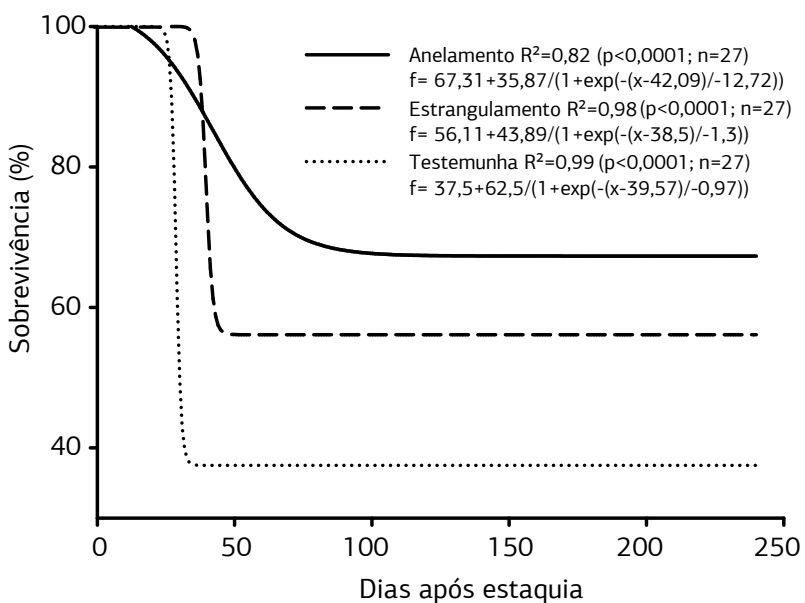

Figura 2. Sobrevivência (\%) de estacas estioladas de abacateiro seleção Viamão, submetidas a dois métodos de obstrução da seiva elaborada, ao longo de 240 dias após o início da estaquia.

novamente estabilizou até os 240 dias. O intervalo entre 20 e 60 dias pode ser considerado como período crítico para a sobrevivência das estacas, pois, nesta fase ocorreu mortalidade acentuada, especialmente naquelas do tratamento testemunha, onde sobreviveram somente $37 \%$ das estacas. Apesar de, aos 60 dias, as mudas terem sido transplantadas para sacos plásticos com capacidade para $5 \mathrm{~L}$ de substrato e, aos 75 dias, terem sido retiradas da câmara de nebulização intermitente e levadas para uma casa de vegetação telada, a sobrevivência não foi afetada, durante e após esses procedimentos.

Através de análises de regressão do número de folhas das estacas ao longo do tempo, em função dos procedimentos de obstrução da seiva elaborada, foram obtidas equaçóes que originaram curvas de natureza sigmoidal e exponencial (Figura 3). Verificou-se que, nos primeiros dias após a realização da estaquia, houve queda pronunciada das folhas das estacas, as quais inicialmente eram quatro. A partir do $30 .^{\circ}$ dia, nos tratamentos anelamento e estrangulamento, respectivamente, as estacas emitiram folhas novas, ao passo que nas estacas sob tratamento testemunha, a emissão de folhas novas só iniciou a partir dos 80 dias aproximadamente, porém foi bem mais lenta do que nos demais tratamentos. Essa diferença de resposta, possivelmente, deve-se à maior quantidade de substâncias de reserva, as quais haviam sido armazenadas nas estacas que tiveram tratamento prévio de obstrução da seiva elaborada (Oliveira et al., 2000). Em consequência, pode ser que tenham emitido maior número e volume de raízes, possibilitando a absorção de água e tendo assim maior desenvolvimento vegetativo em relaçáo ao tratamento testemunha.

Embora não tenha sido avaliado o desenvolvimento do sistema radicular, no fim do experimento foram retiradas algumas mudas dos recipientes e observadas,

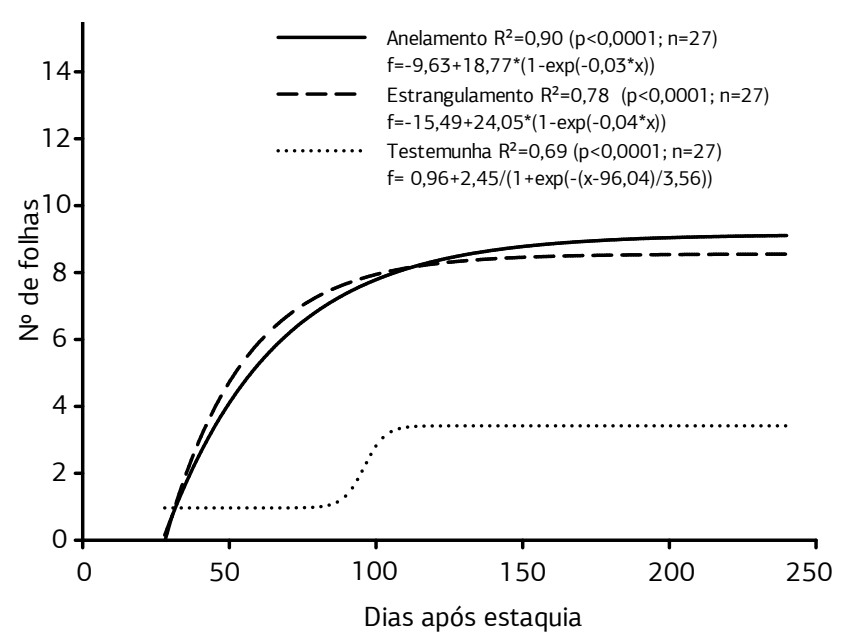

Figura 3. Número médio de folhas presentes em mudas de estacas estioladas de abacateiro seleção Viamão, submetidas a dois métodos de obstrução da seiva elaborada, ao longo de 240 dias após a estaquia.

podendo-se verificar, na figura 4, que a formação de raízes, nas mudas sobreviventes, pode ser considerada satisfatória nos três sistemas de preparo dos ramos que originaram as estacas.

Considerando os resultados deste experimento e os dados disponíveis na bibliografia, pode-se salientar a importância do estiolamento no processo de produçấo de mudas de difícil enraizamento, como é o caso do abacateiro. Não só o estiolamento, mas também o anelamento ou o estrangulamento do caule confirmam-se como técnicas eficientes para que se tenha sucesso na propagaçáo dessa espécie. Para reforçar essas observaçóes, Silveira et al. (2004) obtiveram $62,5 \%$ de estacas enraizadas, combinando o uso de AIB com anelamento e estiolamento dos ramos de abacateiro 'Ouro Verde'. Barrientos-Priego

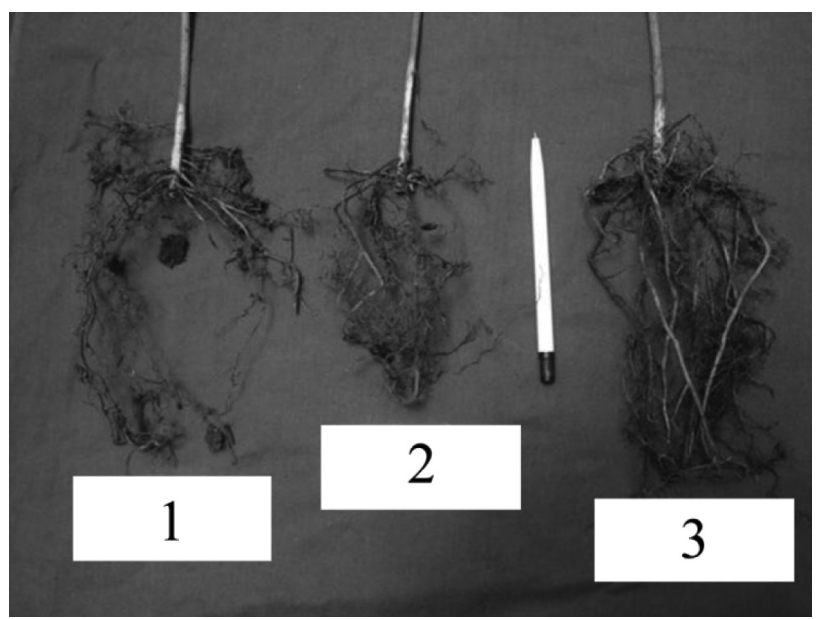

Figura 4. Sistema radicular de mudas de abacateiro seleção Viamão, obtidas a partir de estacas estioladas submetidas a dois métodos de obstruçáo da seiva elaborada ( 1 - testemunha; 2 - estrangulada; 3 - anelada) e acondicionadas em tubos de PVC de $15 \mathrm{~cm}$ de altura para o substrato de enraizamento, um ano após o início da estaquia. 
et al. (1986) testaram diferentes combinaçôes entre as técnicas de estiolamento, anelamento e aplicação de auxinas em estacas estioladas das cultivares Fuerte e Colin V-33 sendo observado que as três técnicas conjuntas proporcionaram as melhores taxas de enraizamento (90-92\%), no entanto, o estiolamento foi considerado a principal técnica para melhorar o enraizamento, seguido pelo anelamento da casca e aplicação de auxina. Resultados semelhantes foram citados por Delargy e Wright (1978) em macieira, no qual o anelamento só potencializou o enraizamento quando utilizado em conjunto com o estiolamento.

\section{CONCLUSÃO}

O prévio anelamento ou estrangulamento da casca de ramos estiolados de abacateiro, para a propagação da seleção Viamão por estaquia, aumentam a sobrevivência e o crescimento de mudas. A altura do recipiente não influencia a sobrevivência e o crescimento das mudas.

\section{REFERÊNCIAS}

AGUSTI, M.; MARTÍNEZ-FUENTES, A.; MESEJO, C.; JUAN, M.; ALMELA, V. Laranja-Tangerina-Tangor: Clima, solo, técnicas de cultivo, desbaste, anelamento e auxinas na produçáo de citros de primeira qualidade. Porto Alegre: Cinco Continentes Editora, 2007.

BARRIENTOS-PRIEGO, A.; BORYS, M.W.; BARRIENTOSPÉREZ, F. Rooting of avocado cuttings (Persea americana Mill.) cvs. Fuerte and Colin V-33. California Avocado Society, v.70, p.157-163, 1986 .

CASTRO, A.M; KERSTEN, E. Influência do anelamento e do estiolamento de ramos na propagaçáo da laranjeira 'Valência' (Citrus sinensis Osbeck) através de estacas. Scientia Agricola, v.53, p.2-3, 1996.

DELARGY, J.A.; WRIGHT, C.E. Root formation in cuttings of apple (cv. Bramley's seedling) in relation to ringbarking and etiolation. New Phytologist, v.81, p.117-127, 1978.

FACHINELLO, J.C.; LUCCHESI, A.A.; GUTIERREZ, L.E. Influência do anelamento na nutrição e no enraizamento de estacas lenhosas do porta-enxerto 'Malling-Merton 106'. Pesquisa Agropecuária Brasileira, v.23, p.1025-1031, 1988.
FACHINELLO, J.C.; HOFFMANN, A.; NACHTIGAL, J.C.; KERSTEN, E.; FORTES, G.R.L. Propagação de plantas frutíferas de clima temperado. Pelotas: UFPEL, 1995, 178p.

FACHINELLO, J.C.; HOFFMANN, A.; NACHTIGAL, J.C. Propagação de plantas frutíferas. Brasília: Embrapa Informação Tecnológica, 2005. 221p.

FAO. FAOSTAT. Disponível em: http://faostat.fao.org. Acesso em: $23 / 8 / 2010$

HARTMANN, H.T.; KESTER, D.E.; DAVIES JUNIOR, F.T; GENEVE, R.L. Plant propagation: principles and practices. 7. ed. New Jersey: Prentice Hall, 2002. 880p.

ITOH, A.; YAKAMURA, T.; KANZAKI, M.; OHKUBO, T.; PALMIOTTO, P.A.; LAFRANKIE, J.V.; KENDAWANG, J.J.; LEE, H.S. Rooting ability of cuttings relates to phylogeny, habitat preference and growth characteristics of tropical rainforest trees. Forest Ecology and Management, v.168, p.275-287, 2002.

KADMAN, A.; BEN YA'ACOV, A. A review of experiments on some factors influencing the rooting of avocado cuttings. California Avocado Society, v.49, p.67-72, 1965.

KOLLER, O.C. Abacate - Produção de mudas, Instalação e manejo de pomares, colheita e pós-colheita. Porto Alegre: Cinco Continentes, 2002. 149p.

OlIVEIRA, A.A.; KOLLER, O.C.; MONTER, A.V. Propagação vegetativa de porta-enxertos de abacateiros (Persea sp.) por mergulhia de cepa. Revista Brasileira de Fruticultura, v.22, p.62-65, 2000.

SALISBURY, F.B.; ROSS, C.W. Fisiología Vegetal. México D.F.: Grupo Editorial Iberoamérica, 1994. 759p.

SIGMAPLOT - Exact Graphy for Exact Science. Version 11.0, 2008.

SILVA, F.A.S.; AZEVEDO, C.A.V. Versão do programa computacional Assistat para o sistema operacional Windows. Revista Brasileira de Produtos Agroindustriais, v.4, p. 71-78, 2002.

SILVEIRA, S.V.; SOUZA, P.V.D.; KOLLER, O.C. Propagação do abacateiro por estaquia. Revista Brasileira de Fruticultura, v.26, p.191-192, 2004.

YOUNG, L.B. Vegetative propagation in avocados by means of marcottage and the rooting cuttings. California Avocado Society, v.45, p.63-66, 1961. 